\title{
GERMINAÇÃO E QUALIDADE SANITÁRIA DE SEMENTES DE DEDALEIRO (Lafoensia pacari St. Hil., Lythraceae)
}

\section{GERMINATION AND SANITARY QUALITY OF SEEDS OF DEDALEIRO (Lafoensia pacari St. Hil., Lythraceae)}

\author{
Adriana Martinelli SENEME ${ }^{1}$ \\ Susane HOFFMAN ${ }^{2}$ \\ Edilberto POSSAMA ${ }^{3}$ \\ Carla Pedroso de MORAES ${ }^{4}$
}

\begin{abstract}
RESUMO
O presente trabalho teve por objetivos avaliar substratos e temperaturas para a germinação, verificar o efeito do armazenamento na qualidade fisiológica e avaliar a sanidade de sementes de Lafoensia pacari (St. Hil.). Determinou-se em sementes coletadas em Curitiba (junho/2003): - teor de água $\left(105^{\circ} \mathrm{C} \pm 3^{\circ} \mathrm{C} / 24 \mathrm{~h}\right.$ ); - germinação: sob temperaturas de $20^{\circ} \mathrm{C}$ e $30^{\circ} \mathrm{C}$, em substratos papel de filtro, vermiculita; areia grossa; mistura de substratos (areia grossa + vermiculita) e areia fina; e emergência em areia fina em casa de vegetação. Após as determinações as sementes foram acondicionadas em sacos de papel e armazenadas em dois ambientes: laboratório e câmara $\left(T=20^{\circ} \mathrm{C}\right)$. Após 12 meses de armazenamento, determinouse o teor de água e germinação utilizando-se os mesmos substratos e temperatura de $20^{\circ} \mathrm{C}$. Realizou-se primeira contagem de germinação (15 dias), determinação de massa de matéria seca das plântulas normais (aos 30 dias) e teste de sanidade ("Blotter test") em papel-filtro $\left(T=22-25^{\circ} \mathrm{C}\right)$. A análise estatística para os testes antes do armazenamento foi realizada em delineamento inteiramente casualizado e após armazenamento utilizou-se um esquema fatorial $2 \times 5$ (armazenamento e substratos); em ambos os experimentos utilizaram-se seis repetições de 30 sementes para cada tratamento e a comparação de acordo com Tukey $(P>0,05)$. As melhores condições para a germinação são temperatura de $20{ }^{\circ} \mathrm{C}$ e substrato areia; o armazenamento em câmara contribui para a manutenção da germinação das sementes e os fungos encontrados nas sementes foram: Aspergillus niger, Fusarium semitectum e Penicilium sp.
\end{abstract}

Palavras-chave: sementes; recomposição florestal; espécie arbórea.

\begin{abstract}
The present work had for objective to evaluate substrata and temperatures for the germination, to verify the effect of the storage in the physiologic quality and to evaluate the sanity of seeds Lafoensia pacari (St. Hil.). Was determined, in seeds collected in Curitiba (junho/2003): - moisture content $\left(105^{\circ} \mathrm{C}+3{ }^{\circ} \mathrm{C} / 24 \mathrm{~h}\right.$ ); - germination: under temperatures of $20{ }^{\circ} \mathrm{C}$ and $30{ }^{\circ} \mathrm{C}$, in substrata filter paper, vermiculite; thick sands; mixture of substrata (thick sands + vermiculite) and fine sands; evaluation to the 35 days after installation; - emergency in fine sand at green house. After the determinations the seeds were conditioned in paper sacks and stored in two ambient: laboratory and camera $\left(T=20^{\circ} \mathrm{C}\right)$. To the 12 months, was determined the moisture content and germination being used the same substrata and temperature of $20^{\circ} \mathrm{C}$. First counting of germination (15 days), determination of the weight of dry matter of the normal seedlings (to the 30 days) and sanity test ("Blotter test") in paper-filter $\left(\mathrm{T}=22-25^{\circ} \mathrm{C}\right)$. The statistical analysis after collection was in a complete randomized design and after storage an factorial $2 \times 5$ was used (storage and substrata); in both experiments six repetitions of 30 seeds were used for each treatment and the mean comparison with Tukey test $(P>0,05)$. The best conditions for the germination are temperature of $20{ }^{\circ} \mathrm{C}$ and sands substratum; the storage in camera contributes to the maintenance of the germination of the seeds and that the fungus found in seeds were: Aspergillus niger, Fusarium semitectum e Penicilium sp.
\end{abstract}

Key-words: seeds; forest recomposition; tree specie.

\footnotetext{
${ }^{1}$ Engenheira Agrônoma, Doutora em Agronomia, Professora do Curso de Engenharia Agrícola - FACIAGREN-FIES, Curitiba, Paraná, Brasil. Email: adriana.seneme@hotmail.com

${ }^{2}$ Engenheira Agrônoma - Universidade Federal do Paraná (UFPR), Curitiba, Paraná, Brasil. E-mail: susanelf@pop.com.br

${ }^{3}$ Engenheiro Agrônomo, Doutor em Agronomia, Professor - Universidade Federal do Paraná (UFPR), Curitiba, Paraná, Brasil. E-mail: possamai@ufpr.br

${ }^{4}$ Engenheira Agrícola, Mestranda do Programa de Pós-graduação em Produção Vegetal da Universidade Federal do Paraná (UFPR), Rua: John Kennedy, 28, 83.501-160, Curitiba, Paraná, Brasil E-mail: kalengagri@yahoo.com.br. Autora para correspondência.
} 
SENEME, A.M. et al. Germinação e qualidade sanitária de sementes...

\section{INTRODUÇÃO}

O uso de sementes de espécies nativas de alta qualidade é fundamental nos programas de recomposição vegetal, 0 que fortalece a necessidade de se investigar o potencial fisiológico das mesmas.

Lafoensia pacari St. Hil., também conhecida como dedaleiro, louro-da-serra, mangaba-brava, copinho, dedal, entre outros, é uma espécie arbórea nativa com ocorrência nas florestas de altitude, nos estados de Minas Gerais, São Paulo, Mato Grosso do Sul até Santa Catarina. É uma planta decídua, indiferente às condições físicas do solo; ocorre também no cerrado, onde seus exemplares apresentam menor desenvolvimento. Sua dispersão é ampla, porém descontínua, nunca formando grandes populações; produz anualmente grande quantidade de sementes viáveis. Sua madeira pode ser utilizada para obras externas e internas, marcenaria, cabos de ferramentas, moirões, construção civil e tabuado em geral. Apresenta boas características ornamentais, sendo bastante utilizada no paisagismo e na arborização urbana (Lorenzi, 2000). Em Curitiba está entre as 10 espécies mais utilizadas na arborização das ruas (Milano, 1984), pois convive bem com outras espécies e sob a rede elétrica. Também é recomendada para reflorestamentos mistos na recomposição de áreas degradadas (Lorenzi, 2000) e para recomposição de mata ciliar em locais bem drenados ou com inundações periódicas de rápida duração (Carvalho, 2003).

Segundo Hong et al. (1996), o sucesso do armazenamento depende do conhecimento prévio do comportamento fisiológico no armazenamento, já que sementes de diferentes espécies exigem condições específicas para a sua conservação. Trabalhos sobre o comportamento de espécies florestais vêm sendo conduzidos, entre elas Lafoensia pacari (Coelho \& Azevedo, 2000), tentando-se suprir a enorme escassez de informações e publicações de resultados de pesquisas na área.

O presente trabalho teve por objetivo avaliar substratos e temperaturas para a germinação, verificar o efeito do armazenamento na qualidade fisiológica e avaliar a sanidade de sementes de Lafoensia pacari (St. Hil.).

\section{MATERIAL E MÉTODOS}

Frutos e sementes de Lafoensia pacari foram coletados no chão, em vias públicas de Curitiba, embaixo das copas de 10 indivíduos, em 20/06/2003. As sementes foram extraídas após o rompimento dos frutos com o auxílio de um martelo, e em seguida determinou-se o teor de água das sementes segundo prescrições descritas por BRASIL (1992). Posteriormente as sementes foram colocadas sobre folhas de papel, expostas ao ar, no Laboratório de Análise de Sementes do Departamento de Fitotecnia e Fitossanitarismo da Universidade Federal do Paraná (UFPR), durante sete dias e após, submetidas às seguintes determinações: a) ensaio de germinação conduzido em caixas de plástico com tampa e transparentes sob duas temperaturas constantes $\left(20\right.$ e $30{ }^{\circ} \mathrm{C}$ ) sem controle de luminosidade em combinação com cinco substratos: papel de filtro umedecido com água destilada em quantidade igual a 2,5 vezes a massa do papel não hidratado; vermiculita granulometria média esterilizada por 24 h a $120{ }^{\circ} \mathrm{C}\left(25 \mathrm{~g}\right.$ de vermiculita com $65 \mathrm{~cm}^{3}$ de água destilada); areia grossa esterilizada por $24 \mathrm{~h}$ a 120 ${ }^{\circ} \mathrm{C}$; $\quad\left(310 \mathrm{~g}\right.$ umedecida com $80 \mathrm{~cm}^{3}$ de água destilada); mistura de substratos (na proporção em volume de $50 \%$ areia grossa e $50 \%$ de vermiculita granulometria média sendo $156 \mathrm{~g}$ de areia grossa e $13 \mathrm{~g}$ de vermiculita) e; areia fina peneirada, malha $1,7 \mathrm{~mm}$, esterilizada e autoclavada (235 g umedecida com $75 \mathrm{~cm}^{3}$ de água destilada). A avaliação da germinação foi realizada aos 35 dias após o início do teste, tendo em vista que nessa ocasião o número de plântulas normais tornou-se constante; b) emergência em bandejas: semeadura em areia fina esterilizada em casa de vegetação realizando-se a avaliação aos 35 dias após a semeadura. Em seguida, as sementes foram divididas em duas porções iguais e acondicionadas em sacos de papel multifoliado tipo "kraft" e armazenadas em duas condições, em ambiente de laboratório, sem controle de temperatura e em câmara com temperatura constante de $20{ }^{\circ} \mathrm{C}$ e umidade relativa de $65 \%$.

Após 12 meses, as sementes dos dois ambientes foram avaliadas quanto ao teor de água (BRASIL, 1992) e submetidas ao teste de germinação seguindo os mesmos procedimentos, com relação aos substratos, da primeira etapa do experimento, porém utilizando-se apenas temperatura de $20{ }^{\circ} \mathrm{C}$ constante. No teste de germinação, realizou-se ainda a primeira contagem de germinação, aos 15 dias após a instalação do teste, e ao final do mesmo, aos 30 dias, realizou-se a determinação da massa de matéria seca (secagem em estufa a $60^{\circ} \mathrm{C}$ com circulação de ar forçado durante cinco dias), das plântulas normais. Realizou-se ainda o teste de sanidade ("blotter test"), em caixas plásticas, em substrato papel filtro previamente esterilizado e umedecido com água esterilizada e autoclavada, com incubação em ambiente de sala, sob temperatura de 22 a $25^{\circ} \mathrm{C}$; a avaliação e identificação dos fungos foram feitas com microscópio-esteroscópio após sete dias de incubação.

Análise estatística - a análise estatística do experimento antes do armazenamento foi realizada em esquema fatorial $2 \times 5$ (duas temperaturas e cinco substratos); após o armazenamento utilizouse o esquema fatorial $2 \times 5$ (duas condições de armazenamento e cinco substratos). Em ambos os experimentos foram utilizados 0 delineamento inteiramente casualizado com seis repetições, de 30 sementes para cada tratamento, e a comparação das médias foi feita por meio do teste de Tukey $(\mathrm{P}>0,05)$. 
SENEME, A.M. et al. Germinação e qualidade sanitária de sementes...

\section{RESULTADOS E DISCUSSÃO}

\section{Avaliações antes do armazenamento}

O teor de água das sementes no momento da coleta foi $15,2 \%$. Em trabalho realizado por Carvalho et al. (2006) o teor de água encontrado em sementes recém-beneficiadas foi $14,8 \%$. Verificou-se que, para a germinação, houve efeito significativo dos fatores substrato e temperatura, porém não houve interação significativa entre eles (Tabela 1).

TABELA 1 - Resultados médios do teste de germinação de sementes recém colhidas de Lafoensia pacari em função da temperatura e em diferentes substratos (Curitiba, 2004).

\begin{tabular}{cc}
\hline Temperatura $\left({ }^{\circ} \mathrm{C}\right)$ & Germinação (\%) \\
\hline 20 & $66 \mathrm{a}^{1}$ \\
30 & $50 \mathrm{~b}$ \\
\hline Substrato & $43 \mathrm{~b}$ \\
\hline Papel & $42 \mathrm{~b}$ \\
Vermiculita & $69 \mathrm{a}$ \\
Areia grossa & $63 \mathrm{ab}$ \\
Mistura ${ }^{2}$ & $73 \mathrm{a}$ \\
\hline Areia fina & 12,69
\end{tabular}

Coeficiente de variação (\%)

12,69

${ }^{1}$ Médias seguida da mesma letra minúscula, na coluna não diferem entre si $(P>0,05)$ de acordo com o teste de Tukey.

${ }^{2}$ Mistura de substratos (na proporção em volume de $50 \%$ areia grossa e $50 \%$ de vermiculita granulometria média sendo 156 $\mathrm{g}$ de areia grossa e $13 \mathrm{~g}$ de vermiculita)

Verificou-se que os substratos que proporcionaram a maior germinação foram: areia fina $(73 \%)$ e areia grossa $(69 \%)$ e mistura $(63 \%)$; o efeito foi estatisticamente semelhante para esses substratos (Tabela 1). Segundo Ferreira et al. (1990) o substrato apresenta grande influência no processo germinativo sendo que a estrutura, aeração, capacidade de retenção de água e o grau de infestação de patógenos podem variar de um substrato para outro, favorecendo ou prejudicando a germinação da semente. Os substratos vermiculita e o papel de filtro mostraram-se como os menos favoráveis dentre os avaliados.

Segundo Coelho \& Azevedo (2000) sementes de mangava brava foram colocadas para germinar em diferentes substratos vermiculita e terra preta + vermiculita (1:1) proporcionaram maiores emergências de plântulas do que os substratos areia, solo de cerrado e terra preta. Esses resultados foram confirmados por Coelho \& Souza (2001), mas Luchese et al. (2002) verificaram que os substratos areia, terra preta, vermiculita e terra preta + vermiculita e terra preta + areia foram favoráveis para a emergência de plântulas de mangava brava.

A temperatura é outro fator importante que exerce forte influência sobre o processo germinativo, tanto na germinação total, como na velocidade e uniformidade de germinação (Carvalho \& Nakagawa, 2000). Assim, verificou-se que independentemente do substrato utilizado, a temperatura que proporcionou a maior porcentagem de plântulas foi $20^{\circ} \mathrm{C}$ (Tabela 1).

A emergência das plântulas em casa de vegetação se iniciou 22 após a semeadura, sendo que nesta data, verificou-se $5 \%$ de emergência; a porcentagem de emergência aos 35 dias foi de
$47 \%$, valores inferiores aos encontrados por Lorenzi (2000) que citou que a emergência ocorre de 10-15 dias e que geralmente a taxa de germinação está em torno de $60 \%$. De acordo com os resultados obtidos, nas avaliações antes do armazenamento, verificou-se que os substratos que proporcionaram melhores condições para germinação foram areia (fina ou grossa) e mistura e a melhor temperatura foi $20^{\circ} \mathrm{C}$. Em trabalho realizado por Carvalho et al. (2006) a temperatura de $25^{\circ} \mathrm{C}$ em substrato entre areia proporcionou germinação de $56 \%$.

\section{Avaliações após o armazenamento}

O teor de água das sementes após o armazenamento era de $13,5 \%$ e $12,2 \%$ para as sementes armazenadas em ambiente de laboratório e câmara, respectivamente. Houve interação significativa entre ambiente de armazenamento e substratos para todas as variáveis avaliadas (primeira contagem, germinação e massa de matéria seca). Com relação ao vigor avaliado pela primeira contagem de germinação (Tabela 2), verificou-se que para as sementes armazenadas em ambiente de laboratório não houve diferença entre substratos, porém, para aquelas armazenadas em câmara, os substratos mistura e areia-grossa foram os melhores e semelhantes estatisticamente; já o pior desempenho foi observado em papel, com germinação zero. Na natureza, sementes florestais, após a dispersão, devem cair ao solo, sob o folhedo, num ambiente provavelmente úmido, que acaba por envolver a semente, facilitando sua embebição e sua germinação; justificando assim o pior desempenho das sementes em papel, que fornece água, porém em quantidade menor que os demais substratos testados. 
SENEME, A.M. et al. Germinação e qualidade sanitária de sementes...

TABELA 2 - Primeira contagem da germinação (\%) de sementes de dedaleiro (Lafoensia pacari) armazenadas durante 12 meses em condições de ambiente (sem controle) e câmara $\left(20^{\circ} \mathrm{C}\right)$ (Curitiba, 2004).

\begin{tabular}{lccccccc}
\hline & & \multicolumn{3}{c}{ Ambiente } & \multicolumn{3}{c}{ Câmara $\left(20^{\circ} \mathrm{C}\right)$} \\
\hline Papel & 4 & $\mathrm{a}^{1}$ & $\mathrm{~A}$ & 0 & $\mathrm{C}$ & $\mathrm{A}$ \\
Vermiculita & 1 & $\mathrm{a}$ & $\mathrm{B}$ & 10 & $\mathrm{bc}$ & $\mathrm{A}$ \\
Areia grossa & 2 & $\mathrm{a}$ & $\mathrm{B}$ & 20 & $\mathrm{ab}$ & $\mathrm{A}$ \\
Mistura & 6 & $\mathrm{a}$ & $\mathrm{B}$ & 29 & $\mathrm{a}$ & $\mathrm{A}$ \\
Areia fina & 0 & $\mathrm{a}$ & $\mathrm{B}$ & 12 & $\mathrm{~b}$ & $\mathrm{~A}$ \\
\hline
\end{tabular}

$$
\text { Coeficiente de variação (\%) } \quad 54,71
$$

${ }^{1}$ Médias seguida da mesma letra minúscula, na coluna, e maiúscula, na linha, não diferem entre si $(P>0,05)$ de acordo com o teste de Tukey.

${ }^{2}$ Mistura de substratos (na proporção em volume de $50 \%$ areia grossa e $50 \%$ de vermiculita granulometria média sendo 156 $\mathrm{g}$ de areia grossa e $13 \mathrm{~g}$ de vermiculita)

Sementes armazenadas em câmara apresentaram os maiores valores de primeira contagem de germinação (PCG) para todos os substratos avaliados, exceto para papel (Tabela 2 ).

Sementes armazenadas em ambiente apresentaram maiores valores de germinação (Tabela 3) no substrato vermiculita, ainda que semelhante estatisticamente aos substratos areia grossa e mistura; seguido do substrato papel, sendo que o pior desempenho germinativo foi observado no substrato areia fina. Sementes armazenadas em câmara apresentaram germinação semelhante estatisticamente em todos os substratos avaliados.

TABELA 3 - Germinação (\%) de sementes de dedaleiro (Lafoensia pacari) armazenadas durante 12 meses em condições de ambiente (sem controle) e câmara $\left(20^{\circ} \mathrm{C}\right)$ (Curitiba, 2004).

\begin{tabular}{|c|c|c|c|c|}
\hline \multirow[b]{2}{*}{ Papel } & \multicolumn{2}{|c|}{ Ambiente } & \multicolumn{2}{|c|}{ Câmara $\left(20^{\circ} \mathrm{C}\right)$} \\
\hline & $21 b^{1}$ & $A$ & $30 \mathrm{a}$ & $A$ \\
\hline Vermiculita & $47 \mathrm{a}$ & A & 42 a & A \\
\hline Areia grossa & $32 a b$ & B & $49 a$ & $A$ \\
\hline Mistura & $39 a b$ & A & $54 a$ & $A$ \\
\hline Areia fina & $3 c$ & B & $46 a$ & A \\
\hline
\end{tabular}

Coeficiente de Variação (\%)

20,03

\footnotetext{
${ }^{1}$ Médias seguida da mesma letra minúscula, na coluna, e maiúscula, na linha, não diferem entre si $(P>0,05)$ de acordo com o teste de Tukey.

${ }^{2}$ Mistura de substratos (na proporção em volume de $50 \%$ areia grossa e $50 \%$ de vermiculita granulometria média sendo 156
} $\mathrm{g}$ de areia grossa e $13 \mathrm{~g}$ de vermiculita)

O local de armazenamento não influenciou a germinação, exceto para o substrato areia (fina e grossa), em que as sementes armazenadas em câmara apresentaram germinação superior àquelas em ambiente (Tabela 3). Os valores de germinação obtidos após o armazenamento foram inferiores ao observados por Carvalho (1994). Sementes de dedaleiro tiveram decréscimos de germinação após 10 meses de armazenamento segundo Coelho \& Azevedo (2000).

Em levantamento realizado por Carvalho (1978) verificou-se que as sementes de dedaleiro apresentaram germinação inicial de $80 \%$ e quando armazenadas em sacos plásticos, em sala e em câmara fria (temperatura entre 20 a $25^{\circ} \mathrm{C}$ e a umidade do ambiente era de saturação), tiveram germinação de 76 e 74\%, respectivamente. Em outro trabalho com a mesma espécie, Capelanes (1989) verificou germinação de $50 \%$ em laboratório (temperatura do ambiente oscilando de 20 a $35^{\circ} \mathrm{C}$ ) logo após $\mathrm{o}$ beneficiamento e após o armazenamento (durante 20 meses em câmara fria a $10^{\circ} \mathrm{C}$ ) apresentaram $60 \%$ de germinação.

A massa de matéria seca das plântulas (Tabela 4) foi influenciada pelo substrato utilizado somente em sementes armazenadas em ambiente, sendo a areia fina o substrato menos favorável quando comparados ao papel, areia grossa e mistura. Sementes armazenadas em ambiente de laboratório apresentaram maiores valores de massa de matéria seca (MS) em todos os substratos avaliados, exceto para a areia fina . 
SENEME, A.M. et al. Germinação e qualidade sanitária de sementes...

TABELA 4 - Massa de matéria seca de plântulas normais (g plântula ${ }^{-1}$ ) originadas de sementes de dedaleiro (Lafoensia pacari) armazenadas durante 12 meses em condições de ambiente (sem controle) e câmara $\left(20^{\circ} \mathrm{C}\right)$ (Curitiba, 2004).

\begin{tabular}{lcccccccc}
\hline & \multicolumn{3}{c}{ Ambiente } & \multicolumn{3}{c}{ Câmara $\left(20^{\circ} \mathrm{C}\right)$} \\
\hline Papel & 0,21 & $\mathrm{a}^{1}$ & $\mathrm{~A}$ & 0,02 & $\mathrm{a}$ & $\mathrm{B}$ & \\
Vermiculita & 0,18 & $\mathrm{ab}$ & $\mathrm{A}$ & 0,02 & $\mathrm{a}$ & $\mathrm{B}$ & \\
Areia grossa & 0,21 & $\mathrm{a}$ & $\mathrm{A}$ & 0,03 & $\mathrm{a}$ & $\mathrm{B}$ & \\
Mistura & 0,28 & $\mathrm{a}$ & $\mathrm{A}$ & 0,02 & $\mathrm{a}$ & $\mathrm{B}$ & \\
Areia fina & 0,06 & $\mathrm{~b}$ & $\mathrm{~A}$ & 0,02 & $\mathrm{a}$ & $\mathrm{A}$ & \\
\hline
\end{tabular}

Coeficiente de Variação (\%)

47,80 ${ }^{1}$ Médias seguida da mesma letra minúscula, na coluna, e maiúscula, na linha, não diferem entre si (P>0,05) de acordo com
o teste de Tukey.
${ }^{2}$ Mistura de substratos (na proporção em volume de $50 \%$ areia grossa e $50 \%$ de vermiculita granulometria média sendo 156
$\mathrm{~g}$ de areia grossa e $13 \mathrm{~g}$ de vermiculita)

Os fungos que atacam sementes são divididos em fungos de campo e armazém. Os fungos de armazém, principalmente, os gêneros Aspergillus e Penicillium são adaptados com ambiente de baixa umidade, se desenvolvendo em materiais cuja umidade esteja em equilíbrio com a umidade relativa de 65-90\% (Lázzari, 1993). Os principais danos causados são decréscimos na germinação, transformação bioquímica, produção de toxinas e modificações celulares; quaisquer dessas mudanças podem ocorrer sem que o fungo se torne visível a olho nú.

Os patógenos encontrados nas sementes de dedaleiro após o armazenamento durante 12 meses foram Aspergillus niger (em ambiente de laboratório) e Aspergillus niger, Fusarium semitectum e Penicilium sp. (em câmara a $20^{\circ} \mathrm{C}$ ) com valores máximos de $1 \%$.

De acordo com os resultados obtidos neste experimento, quando as sementes foram armazenadas em câmara todos os substratos utilizados tiveram o mesmo efeito na primeira contagem de germinação (15 dias) e germinação (30 dias); as plântulas normais (30 dias) tiveram menor massa seca quando comparadas a aquelas armazenadas em ambiente, exceto para o substrato areia fina.

\section{CONCLUSÕES}

As melhores condições para a germinação de sementes de Lafoensia pacari (St. Hill.) são temperatura de $20^{\circ} \mathrm{C}$ e substrato areia;

$\mathrm{O}$ armazenamento em câmara a $20^{\circ} \mathrm{C}$ por 12 meses contribui para a manutenção da germinação das sementes;

Os fungos encontrados nas sementes foram: Aspergillus niger, Fusarium semitectum e Penicilium sp.

\section{REFERÊNCIAS}

1. BRASIL, MINISTÉRIO DA AGRICULTURA E REFORMA AGRÁRIA. Regras para análise de sementes. Brasília: SNDA/ DNDV/CLAV, 1992. $365 \mathrm{p}$.

2. CAPELANES, T. M. C. Tecnologia de sementes florestais na Companhia Energética de São Paulo. In: SIMPÓSIO BRASILEIRO SOBRE TECNOLOGIA DE SEMENTES FLORESTAIS. 2., 1989, Atibaia. Anais... São Paulo: Instituto Florestal, 1991. p. 49-47.

3. CARVALHO, L. R.; SILVA, E. A. A.; DAVIDE, A. C. Classificação de sementes florestais quanto ao comportamento no armazenamento. Revista Brasileira de Sementes, v. 28, n. 2, p. 15-25, 2006.

4. CARVALHO, P. E. R. Algumas características ecofisiológicas e silviculturais de quatro espécies florestais no Estado do Paraná. 1978. 170 f. Dissertação (Mestrado em Engenharia Florestal) - Universidade Federal do Paraná, Curitiba, 1978.

5. CARVALHO, P. E. R. Espécies florestais brasileiras: recomendações silviculturais, potencialidades e uso da madeira. Brasília: EMBRAPA - CNPF, 1994. 640 p.

6. CARVALHO, P. E. R. Espécies arbóreas brasileiras. Curitiba: EMBRAPA - CNPF/SPI, 2003. v. 1.

7. CARVALHO, N. M., NAKAGAWA, J. (Eds.). Sementes: ciência, tecnologia e produção. 4. ed. Jaboticabal: FUNEP, 2000. $588 \mathrm{p}$.

8. COELHO, M. F. B.; AZEVEDO, R. A. B. Efeito de tratamentos pré-germinativos e substratos em Lafoensia pacari Saint. Hil - Lythraceae. In: SIMPÓSIO DE PLANTAS MEDICINAIS DO BRASIL, 16., 2000, Recife. Anais... Recife: UFPE, 2000. p. 72

9. COELHO, M. F. B.; SOUZA, S. S. G. L. Emergência de plântulas de mangava brava (Lafoensia pacari St. Hill. Lythraceae) em diferentes substratos. In: ENCONTRO DE INICIAÇÃO CIENTÍFICA, 9., 2001, Cuiabá. Anais... Cuiabá: UFMT, 2001. p. 224

10. FERREIRA, F. R.; BIANCO, S.; SADER, R. Germinação de semente de uva japonesa (Hovevia dulcis TUMBERG) e biribá (Rollinia mucosa (JACK) baill). Revista Brasileira de Sementes, v. 12, n. 1, p. 73-81, 1990. 
SENEME, A.M. et al. Germinação e qualidade sanitária de sementes...

11. HONG, T. D.; LININGTON, S.; ELLIS, R. H. Seed storage behavior: a compendium. Rome: International Pant Genetic Resources Institute, 1996. 55 p. (Technical Bulletin, 1).

12. LÁZZARI, F. A. Umidade, fungos e micotoxinas na qualidade de sementes, grãos e rações. 1. ed. Curitiba, 1993. $133 \mathrm{p}$.

13. LORENZI, H. Árvores brasileiras: manual de identificação e cultivo de plantas arbóreas nativas do Brasil. 3. ed. Nova Odessa: Instituto Plantarum, 2000. v. 1.

14. LUCHESE, M.; COELHO, M. F. B.; CALDEIRA, S. A. F. Emergência de plântulas de mangava brava (Lafoensia pacari St. Hill.) em diferentes substratos. Cuiabá: UFMT, 2002. (Relatório CNPq/PIBIC/UFMT).

15. MILANO, M. S. Avaliação e análise da arborização de ruas de Curitiba, PR. 1984. 130 f. Dissertação (Mestrado em Engenharia Florestal) - Universidade Federal do Paraná, Curitiba, 1984.

Recebido em 15/10/2008

Aceito em 10/09/2009 